\title{
Sestrin2 protects dendritic cells against endoplasmic reticulum stress-related apoptosis induced by high mobility group box-1 protein
}

\author{
Li-Xue Wang ${ }^{1,2}$, Xiao-Mei Zhu', Yi-Nan Luo ${ }^{1}$, Yao Wu', Ning Dong ${ }^{1}$, Ya-lin Tong ${ }^{3}$ and Yong-Ming Yao ${ }^{1,2,4}$
}

\begin{abstract}
Sestrin2 (SESN2) is a highly evolutionary conserved protein and involved in different cellular responses to various stresses. However, the potential function of SESN2 in immune system remains unclear. The present study was designed to test whether dendritic cells (DCs) could express SESN2, and investigate the underlying molecular mechanism as well as its potential significance. Herein, we firstly reported that SESN2 was expressed in DCs after high mobility group box-1 protein (HMGB1) stimulation and the apoptosis of DCs was obviously increased when SESN2 gene silenced by siRNA. Cells undergone SESN2-knockdown promoted endoplasmic reticulum (ER) stress (ERS)-related cell death, markedly exacerbated ER disruption as well as the formation of dilated and aggregated structures, and they significantly aggravated the extent of ERS response. Conversely, overexpressing SESN2 DCs markedly decreased apoptotic rates and attenuated HMGB1-induced ER morphology fragment together with inhibition of ERS-related protein translation. Furthermore, sesn $2^{-1}$-deficient mice manifested increased DC apoptosis and aggravated ERS extent in septic model. These results indicate that SESN2 appears to be a potential regulator to inhibit apoptotic ERS signaling that exerts a protective effect on apoptosis of DCs in the setting of septic challenge.
\end{abstract}

\section{Introduction}

Dendritic cells (DCs), the most important potent antigen-presenting cells, are unique in their capacity to prime naive $\mathrm{T}$ cells and initiate immune response linking the innate immunity system with adaptive immune response $^{1,2}$. Several reports have demonstrated that the profound depletion in the number of DCs, mainly suffered from apoptosis, bears mostly liability in the pathogenesis of sepsis and inflammatory diseases, and is potentially associated with the fatal outcome in septic or severe trauma patients ${ }^{3-7}$. However, the molecular regulatory mechanisms underlying the functional statues of DCs are

\footnotetext{
Correspondence: Yong-Ming Yao (c_ff@sina.com)

${ }^{1}$ Trauma Research Center, Fourth Medical Center of the Chinese PLA General Hospital, Beijing 100048, PR China

${ }^{2}$ First Medical Center of the Chinese PLA General Hospital, Beijing 100853, PR China

Full list of author information is available at the end of the article These authors contributed equally: Li-Xue Wang, Xiao-Mei Zhu Edited by H.-U. Simon
}

poorly known at present. Nowadays, increasing evidences highlight the significant impact of endoplasmic reticulum (ER) stress (ERS) on maintaining cellular stability ${ }^{8}$. Unfolded protein response (UPR), triggered by the accumulation of unfolded or misfolded proteins within the lumen of ER in ERS, determines the cell destiny by adjusting the balance between cell adaption to stress and cell death resulting from disorder in ER homeostasis ${ }^{9,10}$. Recent studies have documented that ERS has important significance in functional modulation of $\mathrm{DCs}^{11,12}$.

Our previous studies proved that the overwhelming ERS response in splenic DCs in severe thermal injuries could be the main cause to initiate excessive apoptosis and dysfunction of DCs, thereby resulting in immunosuppression and even death ${ }^{13-15}$. The pathophysiological mechanism is highly related to an important late-acting cytokine high mobility group box-1 protein (HMGB1), which is increased markedly in sepsis and plays an important role in provoking inflammation and immune

\section{(c) The Author(s) 2020}

(c) Open Access This article is licensed under a Creative Commons Attribution 4.0 International License, which permits use, sharing, adaptation, distribution and reproduction cc) in any medium or format, as long as you give appropriate credit to the original author(s) and the source, provide a link to the Creative Commons licence, and indicate if changes were made. The images or other third party material in this article are included in the article's Creative Commons licence, unless indicated otherwise in a credit line to the material. If material is not included in the article's Creative Commons licence and your intended use is not permitted by statutory regulation or exceeds the permitted use, you will need to obtain permission directly from the copyright holder. To view a copy of this licence, visit http//creativecommons.org/licenses/by/4.0/. 
responses. Moreover, our previous studies demonstrated that HMGB1-induced ERS-related apoptosis in splenic DCs and had a complicated mechanism in mediating immune function of DCs. However, no therapeutic target in ERS signaling pathways has been elucidated in the immunomodulation of DCs.

Sestrins (SESNs), a highly conserved protein family, can be induced by various stresses, including oxidative stress $^{16}$, DNA damage ${ }^{17}$, and hypoxia ${ }^{18}$. It was reported that SESNs protected cells against various stimuli by regulating autophagy, ERS, metabolism, and apoptosis. As the unique protein in SESNs family, SESN2 was found to be upregulated by the activation of ERS signaling pathways and be an important protective factor on relieving cell injury and cell death ${ }^{19-24}$. We proposed that SESN2 might be one of the favorable factors in immune regulation of DCs under ERS in the setting of sepsis. The present study aimed to verify the protective effects of SESN2 on apoptosis of DCs under stimulation with HMGB1 and during sepsis and tried to identify the key molecules in ERS-related apoptosis signaling pathways.

\section{Results}

\section{HMGB1-induced apoptosis of DC2.4 cells}

DC2.4 cells were treated with various concentrations of HMGB1 for different intervals. As shown in Fig. 1a, b, HMGB1 stimulation in vitro could markedly increase the apoptotic rate of DC2.4 cells at dose of $1-100 \mathrm{ng} / \mathrm{ml}$ and cultured for $8-48 \mathrm{~h}$, showing a time- and dose-dependent manner (all $P<0.05$ ). We further examined level of caspase-3, cleaved-caspase-3, Bax, and Bcl-2 in DC2.4 cells stimulated with HMGB1. HMGB1 (especially at 10 and $100 \mathrm{ng} / \mathrm{ml}$ for $48 \mathrm{~h}$ ) induced caspase-3 activation (cleaved), upregulated Bax protein, and suppressed $\mathrm{Bcl}-2$ expression (Fig. 1c-f, $P<0.05$ ). The $\mathrm{Bax} / \mathrm{Bcl}-2$ ratio was obviously elevated in HMGB1-stimulated groups when compared with the control group at $100 \mathrm{ng} / \mathrm{ml}$ for $48 \mathrm{~h}$ (Fig. 1c-f, $P<0.05$ ).

\section{SESN2 was upregulated in DC2.4 cells with HMGB1- induced ERS}

To investigate the change of SESN2 expression in DCs after HMGB1 stimulation, DC2.4 cells were treated with HMGB1 at different concentrations for various intervals. As shown in Fig. 2, both mRNA and protein levels of SESN2 were upregulated in DC2.4 cells after HMGB1 stimulation. SESN2 mRNA expression in DC2.4 cells was significantly increased after treatment with HMGB1 for 24h (Fig. 2a). Protein levels of SESN2 in DC2.4 cells were obviously upregulated when treated with $10 \mathrm{ng} / \mathrm{ml}$ HMGB1 for $48 \mathrm{~h}$ (Fig. $2 \mathrm{~b}, \mathrm{c}, P<0.05$ ). In addition, we used confocal laser scanning microscopy to further identify the expression of SESN2 protein in DC2.4 cells. Green fluorescence could be observed mainly in the cytoplasm of DC2.4 cells, and SESN2 expression was markedly enhanced after treatment with HMGB1 for $48 \mathrm{~h}$ at different concentrations (Fig. 2d).

\section{Protective effect of SESN2 on DC2.4 cells under HMGB1 stimulation}

DC2.4 cells were transduced with recombinant lentiviruses that carried SESN2 siRNA (knockdown) or SESN2-LV-RNA (overexpression) (Fig. 3a, b). The results showed that protein expression of SESN2 was downregulated in the SESN2 siRNA group and dramatically upregulated in the SESN2 LV-RNA group, when compared with the scramble group (Fig. 3a, b).

To confirm the impact of SESN2 on cell apoptosis, cells were examined with Annexin-V-phycoerythrin (PE)/7AAD quantification assay and Hoechst 33342 staining, respectively. As shown in Fig. 3c, the apoptotic rate of DC2.4 cells with SESN2-siRNA was obviously higher than the scramble group, especially under HMGB1 stimulation (Fig. 3c, $P<0.05$ ). Hoechst 33342 staining also revealed more condensed or fragmented apoptotic nuclei in the SESN2-siRNA group than that in the scramble group (Fig. 3e). Furthermore, activation of caspase-3 and caspase-9 (critical factors of apoptosis) in the SESN2siRNA group was markedly exacerbated when compared to the scramble group (Fig. 3g). Expression levels of the anti-apoptosis protein of $\mathrm{Bcl}-2$ were decreased and the pro-apoptosis protein of Bax were increased after HMGB1 stimulation, and $\mathrm{Bax} / \mathrm{Bcl}-2$ ratio in the SESN2siRNA group was significantly elevated when compared with the scramble group (Fig. $3 g, P<0.05$ ).

On the contrary, the apoptotic rate of DC2.4 cells with SESN2-LV-RNA was effectively reduced in comparison to the scramble group after treatment with HMGB1 (Fig. 3d, f, $P<0.05)$. Levels of cleaved-caspase- 3 and cleaved-caspase- 9 were obviously decreased. The expression of antiapoptosis protein of Bcl-2 was upregulated, while Bax expression was downregulated, and $\mathrm{Bax} / \mathrm{Bcl}-2$ ratio in the SESN2-LV-RNA group was significantly decreased when compared with that in the scramble group (Fig. $3 \mathrm{~h}, P<0.05$ ).

\section{Protective effect of SESN2 on DC2.4 cells was closely related to the inhibition of ERS-related apoptotic pathway Co-localization of SESN2 and ER in DC2.4 cells \\ DC2.4 cells were stained with antibody to SESN2} (green) and ER-tracker probe (red). SESN2 was colocalized with the organelle of ER (Fig. 4a, shown in saffron yellow). The fluorescence intensity of SESN2 was enhanced after treatment with HMGB1 or tunicamycin (TM, prototypical ERS inducer). Meanwhile, result from co-localization using SESN2 antibody (red) and activating transcription factor (ATF)4 antibody (green) or glucose regulated protein (GRP)78 (green) showed that SESN2 could interact with ATF4 not GRP78 to regulate ERS 


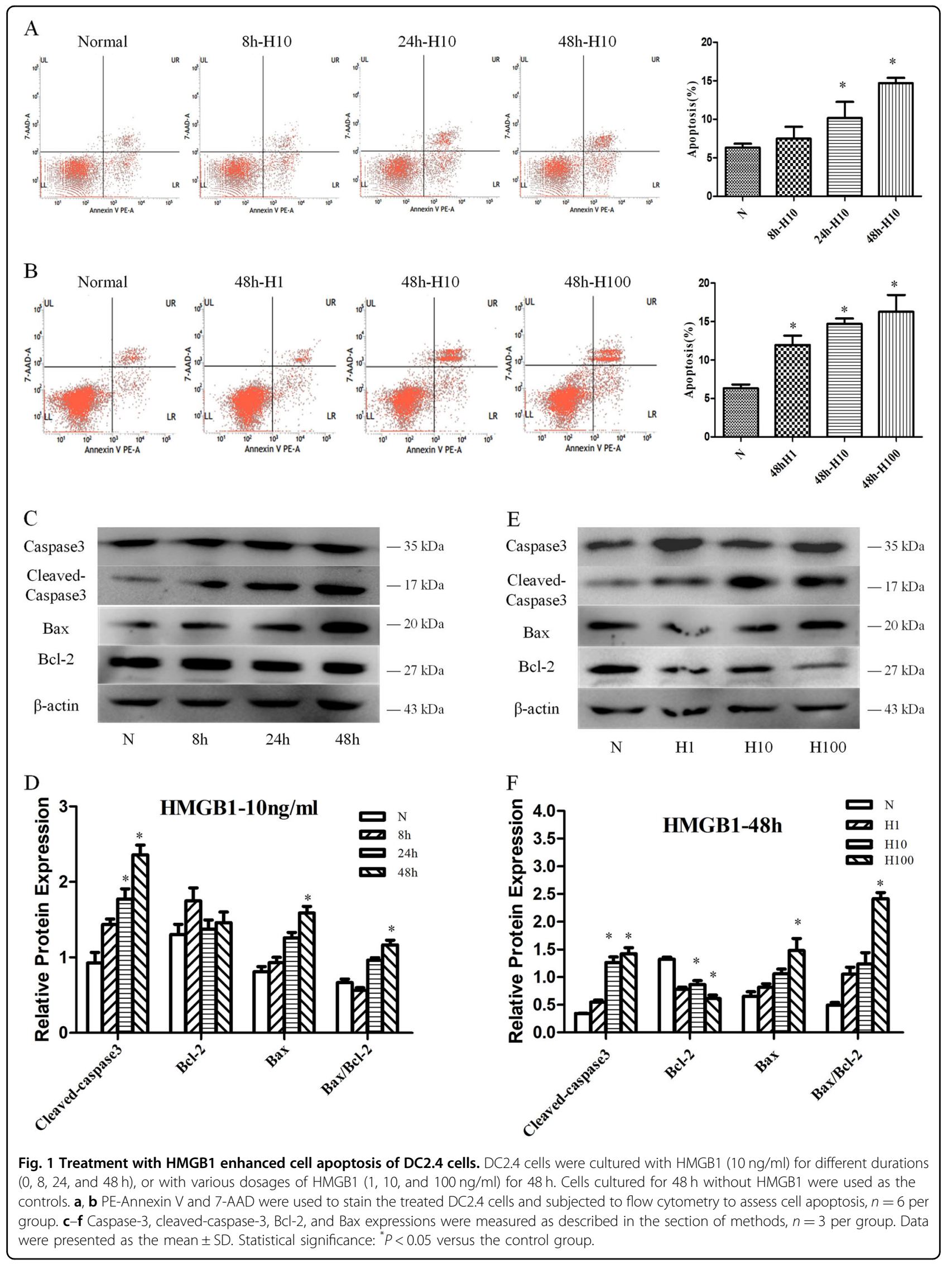



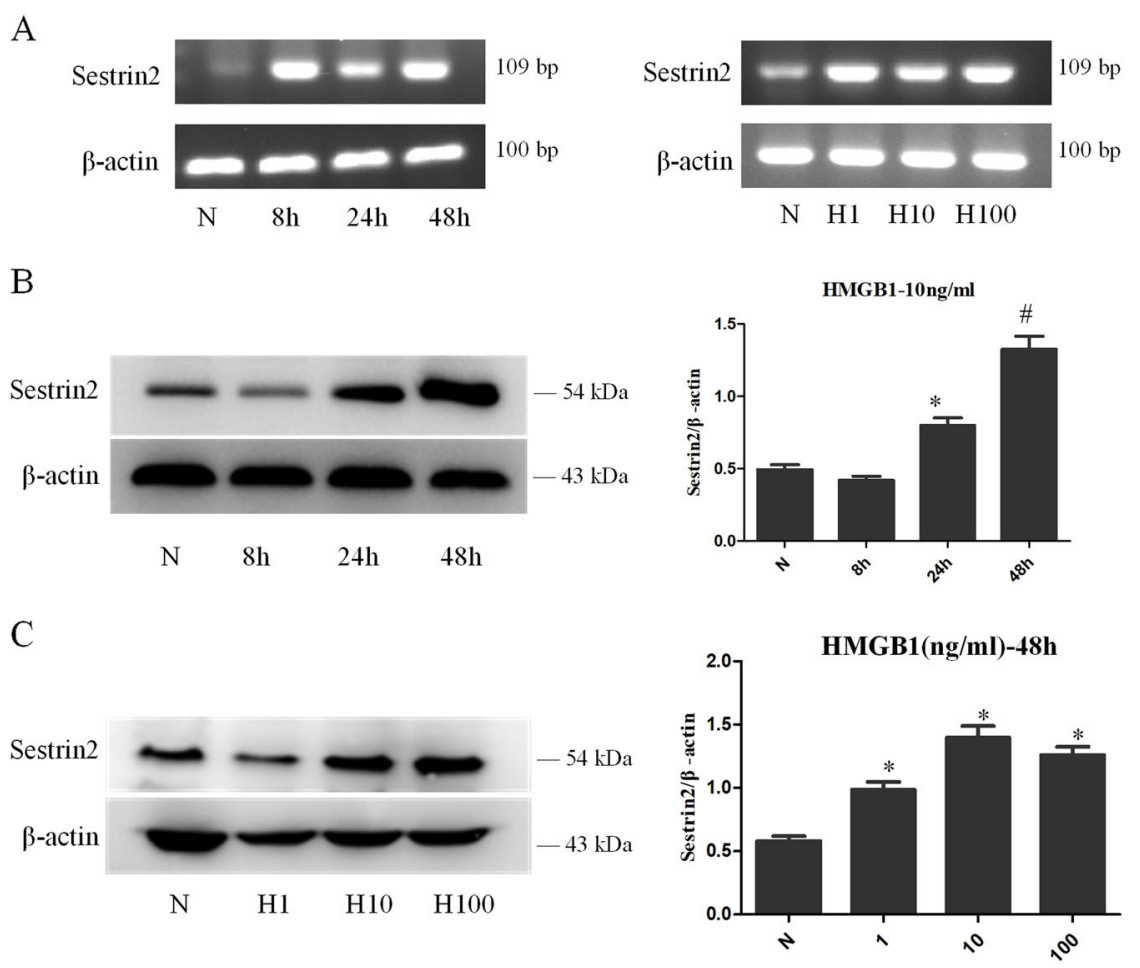

$\mathrm{D}$

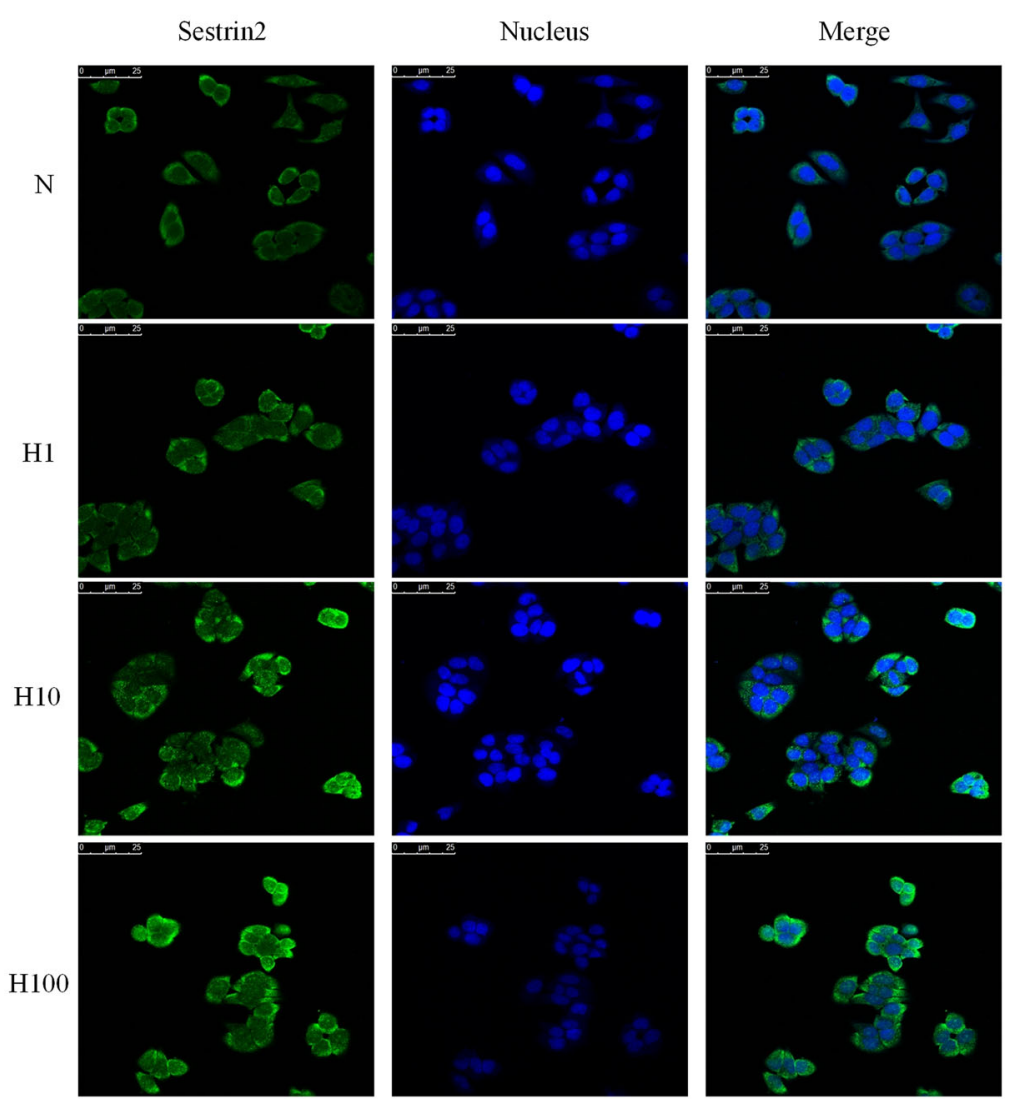

Fig. 2 (See legend on next page.) 
(see figure on previous page)

Fig. 2 HMGB1 upregulated the expression of SESN2 in DC2.4 cells. a SESN2 mRNA expression were analyzed by PCR after DC2.4 cells stimulated with HMGB1 $(10 \mathrm{ng} / \mathrm{ml})$ for different intervals $(0,8,24$, and $48 \mathrm{~h})$, or with various dosages of HMGB1 $(1,10$, and $100 \mathrm{ng} / \mathrm{ml})$ for $48 \mathrm{~h}$. $\beta$-actin served as the internal standard. b, c Protein levels of SESN2 were analyzed by Western blotting after DC2.4 cells stimulated with $10 \mathrm{ng} / \mathrm{ml}$ HMGB1 for different time points or at various concentrations for $48 \mathrm{~h}$. $\beta$-actin served as the internal standard, $n=3$ per group. $\mathbf{d}$ Laser scanning confocal microscopy was employed to observe the expression of SESN2 protein in DC2.4 cells after HMGB1 treatment at various concentrations for $48 \mathrm{~h}$, with FITC labeled SESN2 protein (green) and DAPI stained nucleus (blue) $(\times 600)$, scale bar $=25 \mu \mathrm{m}, n=4$ per group. Data were presented as mean \pm SD of at least three independent experiments. Statistical significance: ${ }^{*} P<0.05,{ }^{\#} P<0.01$ versus the control group.

(Fig. 4b, c, shown in saffron yellow). We further examined co-immunoprecipitation (co-IP) with SESN2 antibody and Western blot analysis showed SESN2 interacted with ATF4 in DC2.4 cells (Fig. 4d).

\section{SESN2-protected DC2.4 cells against ERS-related apoptosis triggered by $T M$}

DC2.4 cells were treated with different concentrations of TM for $48 \mathrm{~h}$, which resulted in significant apoptosis at $2 \mu \mathrm{g} / \mathrm{ml}$ (Fig. 5a, $P<0.05$ ). Accordingly, SESN2 was markedly upregulated after TM stimulation $(0.25-3 \mu \mathrm{g} / \mathrm{ml}$ for $48 \mathrm{~h}$ ) in a dose-dependent manner (Fig. 5b). To investigate the protective effect of SESN2 on ERS-induced apoptosis, DC2.4 cells with SESN2 siRNA or SESN2-LVRNA were treated with $2 \mu \mathrm{g} / \mathrm{ml}$ TM for $48 \mathrm{~h}$. SESN2 gene silence resulted an increased apoptosis when compared with the scramble group (Fig. $5 \mathrm{c}, P<0.05$ ). Conversely, the apoptotic rate was decreased when SESN2 gene was overexpressed (Fig. 5 c, $P<0.05$ ). As an important component of the ERS-mediated apoptosis pathway, C/EBP homologous protein $(\mathrm{CHOP})$ was obviously exacerbated after SESN2 knockdown and levels were lower in the SESN2 overexpression group in comparison with the scramble controls (Fig. 5d, $P<0.05$ ), respectively.

\section{HMGB1-induced apoptosis of DC2.4 cells through ERS- apoptotic pathway}

As shown in Fig. 6a, treatment with 100 ng/ml HMGB1 for $48 \mathrm{~h}$ significantly increased expressions of ERS markers including GRP78 $(P<0.05)$, phosphorylation $(\mathrm{p})$ of protein kinase RNA (PKR)-like ER kinase (PERK), PERK, and ATF4 $(P<0.05)$. Likely, CHOP was obviously increased following HMGB1 stimulation $(P<0.05)$. In addition, apoptotic-related protein $\mathrm{Bax}$ and $\mathrm{Bcl}-2$ were analyzed, and the Bax/Bcl-2 ratio was increased in DC2.4 cells $(P<0.05)$. Thus, PERK-ATF4-CHOP-mediated cell death pathway might be activated in HMGB1-induced DC2.4 cell death.

\section{SESN2-protected DC2.4 cells from excessive ERS response induced by HMGB1}

ERS signaling pathways were examined in HMGB1stimulated DC2.4 cells after SESN2-siRNA or SESN2-LVRNA transfection. Silence of SESN2 markedly aggravated
ERS response and enhanced ERS-related apoptosis. ERS markers including GRP78, p-PERK, and ATF4 were significantly upregulated. Protein level of CHOP, a pivotal component in ERS-related apoptotic pathway, also presented a substantial increase (Fig. 6b). By contrast, overexpression of SESN2 could inhibit ERS induced by HMGB1 with downregulation of ATF4 as well as CHOP and reduction of PERK phosphorylation (Fig. 6c, $P<0.05)$.

We further observed the changes of ER structure after interfering SESN2 expression. As shown in Fig. 6d, alteration and fragmentation of ER could be found in DC2.4 cells stimulated by HMGB1 or TM. Significantly fragmented and lumped changes were noticed in ER morphology of SESN2 silenced DC2.4 cells after treatment with $100 \mathrm{ng} / \mathrm{ml} \mathrm{HMGB1}$ or $2 \mu \mathrm{g} / \mathrm{ml}$ TM for $48 \mathrm{~h}$. While SESN2-LV-RNA transfected DC2.4 cells maintained the structure of ER after HMGB1 or TM stimulation, almost the same interconnected networks as in the scramble group (Fig. 6d).

SESN2 inhibited PERK-CHOP pathway to protect DC2.4 cells against ERS-related cell apoptosis

To further investigate the potential signaling pathways with regard to protective impact of SESN2 on ERS-related cell apoptosis, DC2.4 cells were pretreated with various concentrations of PERK inhibitor (GSK2656157, $0.5-3 \mu \mathrm{mol} / \mathrm{L}$ ) for $1 \mathrm{~h}$, then exposed to $100 \mathrm{ng} / \mathrm{ml}$ HMGB1 for $48 \mathrm{~h}$. Pretreatment with PERK inhibitor obviously attenuated ATF4 expression and reduced SESN2 induction by HMGB1, especially at $2 \mathrm{mmol} / \mathrm{L}$ of GSK2656157 (Fig. 7a). Blockade of PERK signaling pathway significantly decreased SESN2 and CHOP expressions, and diminished the protective actions of SESN2 in both SESN2 silenced and SESN2 overexpressed DC2.4 cells in comparison with the scramble controls (Fig. 7b, c).

\section{The protective impact of SESN2 on DCs in cecal ligation} and puncture (CLP)-induced septic mice

To study the pathophysiological role of SESN2 in vivo, we evaluated the protective effect of SESN2 on splenic DCs in a CLP-induced septic murine model. As shown in Fig. 8a, SESN2 was upregulated in splenic DCs from septic mice at $24 \mathrm{~h}$. Knockout of SESN2 resulted in a higher 


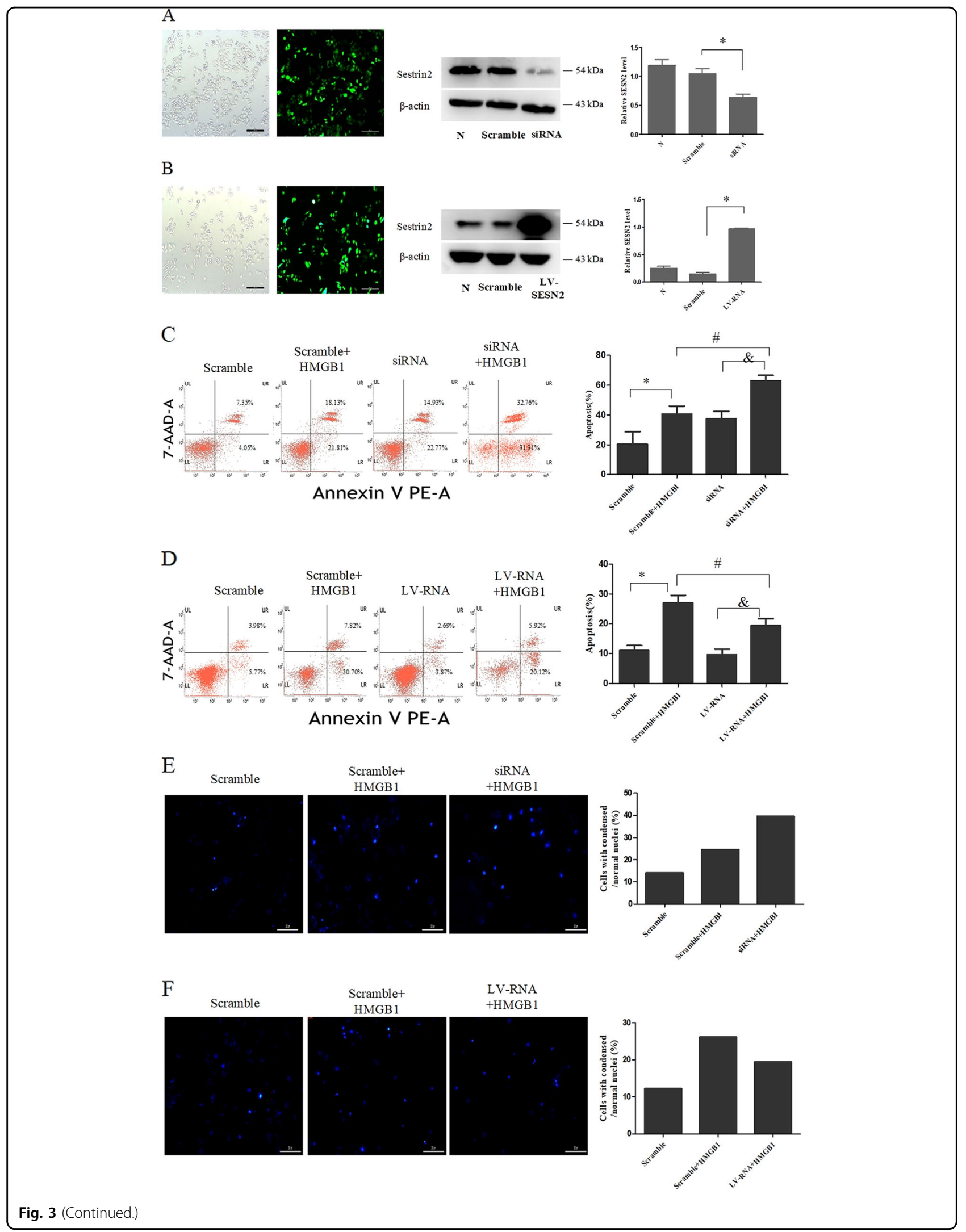




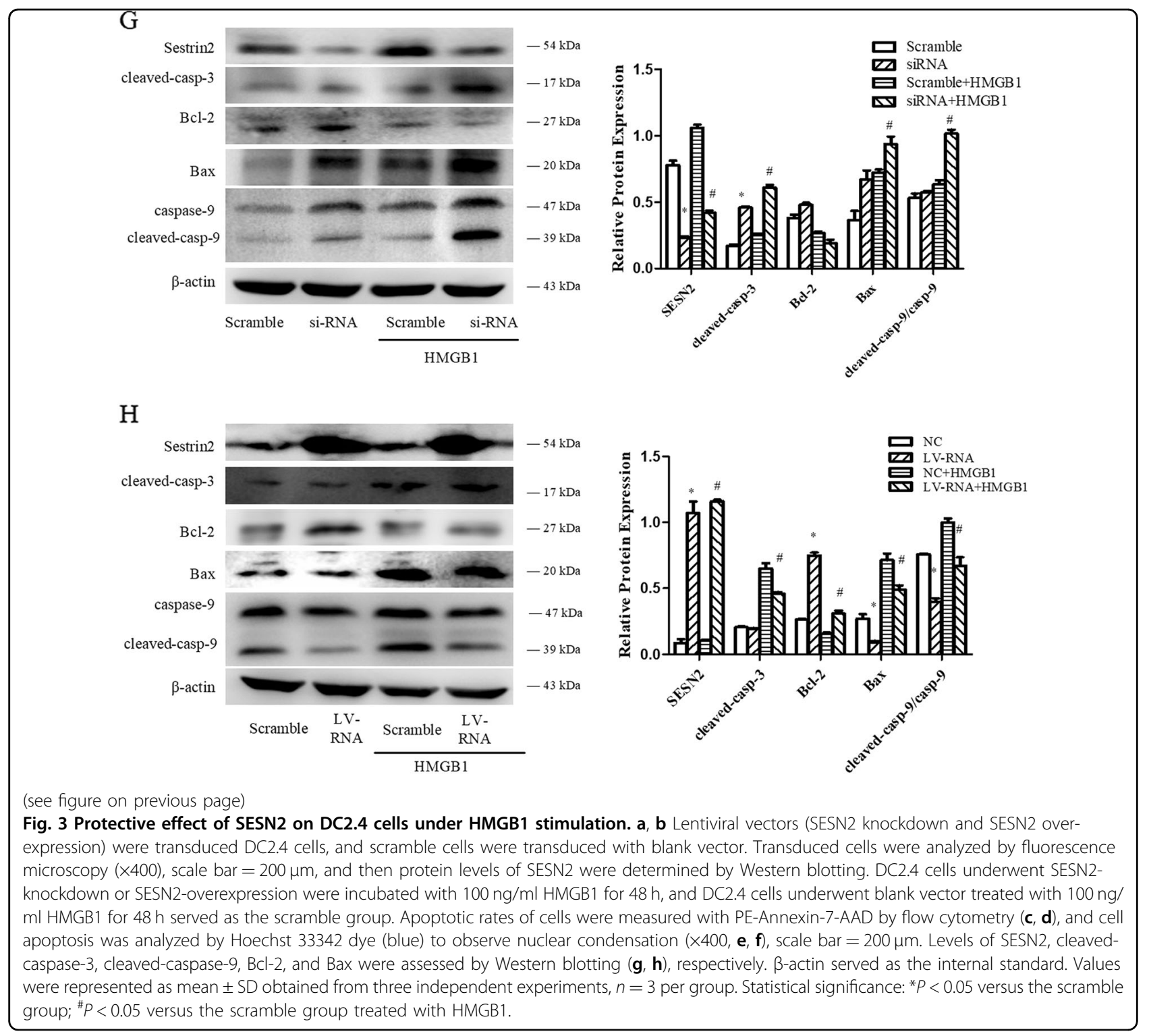

apoptotic rate of DCs after CLP procedure, when compared with wild-type (WT) mice (Fig. 8b, $P<0.05$ ). Accordingly, increases in proapoptotic proteins (BAX and cleaved-caspase-3) and decreases in antiapoptotic protein (Bcl-2) in CLP mice were reinforced in sesn $2^{-1-}$ mice (Fig. 8c).

To further investigate the influence of SESN2 on ERS in DCs in CLP mice, we observed the morphologic changes of ER and the expression of ER chaperones. As shown in Fig. 8d, more extensive fragmented and lumped ER could be found in sesn $2^{-1-}$ DCs, and protein levels of ATF4 and CHOP were also upregulated (Fig. 8d). Moreover, SESN2 deficiency strongly aggravated ERS responses in DCs during sepsis, as evidenced by upregulation of GRP78 and ATF4 in CLP mice (Fig. 8d). In addition, we compared the 24-h survival rate of CLP mice between sesn $2^{-1-}$ mice and WT mice. These results showed that sesn $2^{-1-}$ knockout aggravated CLP-induced mortality at $24 \mathrm{~h}$ (Fig. 8e).

\section{Discussion}

Sepsis was now defined as life-threatening organ dysfunction caused by dysregulated host response to infection $^{25}$. It is well documented that extensive apoptosis of splenic leukocytes, including $\mathrm{T}$ lymphocytes, macrophages, and DCs, occurs in sepsis and endotoxic shock, may contribute to the immunosuppressive characteristic of these disorders ${ }^{26,27}$. DCs are critical potent antigen-presenting cells that are key factors in immune response by initiating $\mathrm{T}$ lymphocytes. Previous studies indicated that the decreased number of splenic DCs in mice suffered from sepsis and blood DCs in 


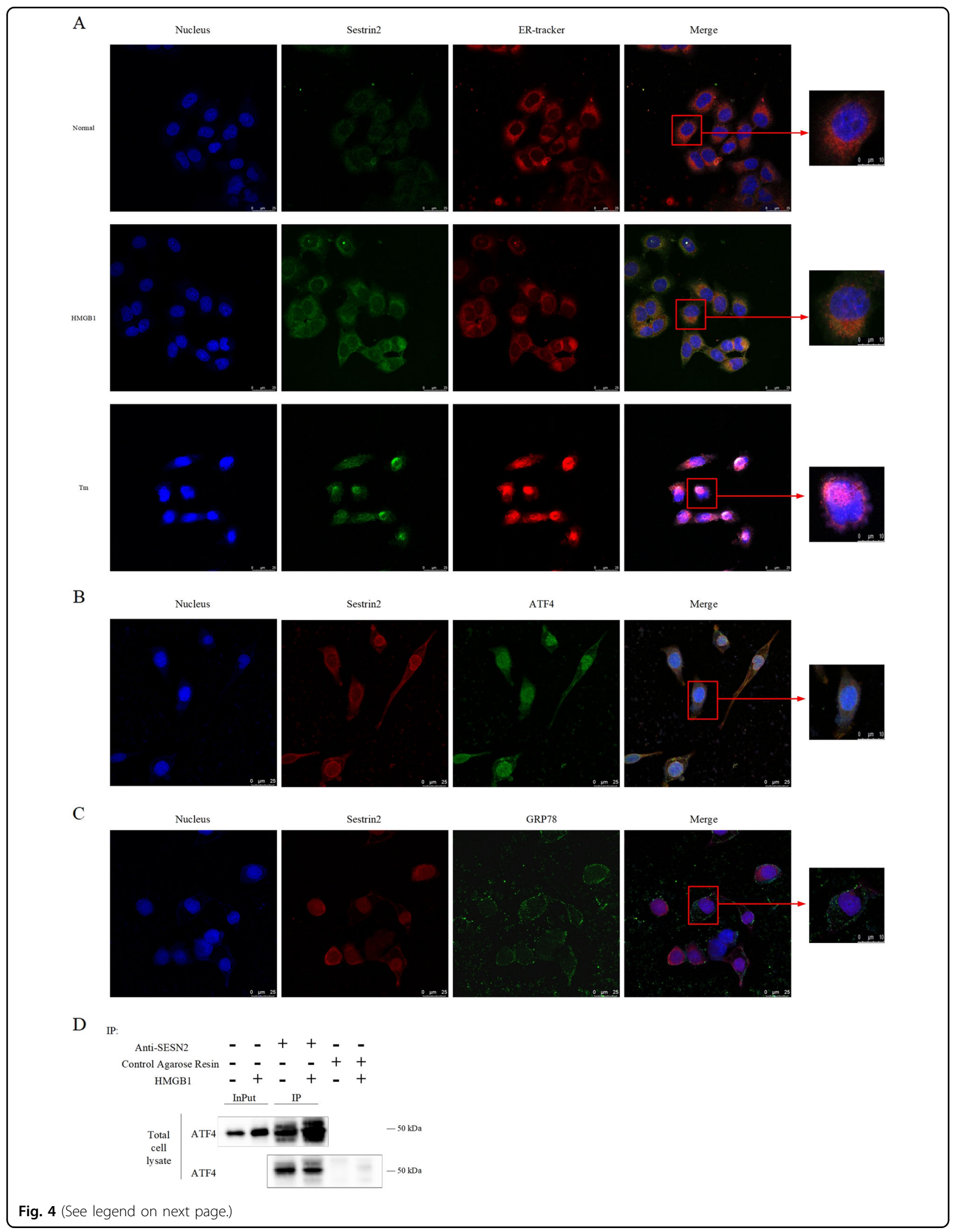


(see figure on previous page)

Fig. 4 Co-localization of SESN2 and ER in DC2.4 cells $(\times 600, \times 1200)$. a Laser scanning confocal microscopy was used to observe SESN2 and ER in DC2.4 cells. It was shown by anti-SESN2 antibodies (green) and ER tracker (red) using indirect immunofluorescence and confocal microscopy. $\mathbf{b}$ It was observed by anti-SESN2 antibodies (red) and ATF4 (green) using indirect immunofluorescence and confocal microscopy. c It was shown by antiSESN2 antibodies (red) and GRP78 (green) using immunofluorescence and confocal microscopy. $\mathbf{d}$ Immunoblot analysis of ATF4 in SESN2 was immunoprecipitated in total cell lysate. Negative control was using control agarose resin. Scale bar $=25 \mu \mathrm{m}$, scale bar $=10 \mu \mathrm{m}, n=3$ per group. Its co-localization was shown in saffron yellow (DAPI stained nucleus, blue).

septic patients played important roles in sepsis-induced immune paralysis ${ }^{28,29}$. The loss of DCs during sepsis appears to be a universal phenomenon, and it acts as a mark of immune depression. Therefore, it is entirely reasonable for us to believe that reduction and prevention of the apoptosis of DCs might improve and reverse the immunosuppressive state in the setting of sepsis. HMGB1, one of the key damage-associated molecular patterns, is an important late-acting inflammatory cytokine of sepsis that can be actively secreted by immune cells or passively released by injured or necrotic cells. It has been documented that HMGB1 is critically involved in host immune dysfunction and various diseases $^{30-32}$, and it acts as a potent mediator of DC activation, maturation as well as survival ${ }^{13-15,33-35}$. In the present study, we investigated the proapoptotic effect of HMGB1 stimulation on DC2.4 cells in vitro, showing a time-dependent and dose-dependent manner. It is wellknown that both antiapoptotic protein of $\mathrm{Bcl}-2$ and proapoptotic protein of Bax are two members of Bcl-2 family, and Bax can activate the downstream signal caspase- 3 promoting apoptosis ${ }^{36}$. Our results revealed that treatment with HMGB1 $(10-100 \mathrm{ng} / \mathrm{ml}$ for $48 \mathrm{~h}$ ) markedly induced activation of caspase-3, upregulation of Bax, and downregulation of Bcl-2.

Recently, SESN2 is reportedly involved in many cellular responses to various stresses. In our study, stimulation with HMGB1 for $48 \mathrm{~h}$ could obviously induce the upregulation of SESN2 in DC2.4 cells in a dose-dependent pattern in vitro, and the expression of SESN2 was enhanced at $24 \mathrm{~h}$ after CLP in vivo. Many experiments have proved that SESN2 exerts cytoprotective function and prevents cell apoptosis via different mechanisms. For instance, Ben-Sahra et al. ${ }^{37}$ found that SESN2 protected cells from energetic stress-mediated apoptosis by maintaining the energy homeostasis. Perk et al. ${ }^{20}$ showed that SESN2-knockdown hepatocytes were hypersusceptible to obesity-induced apoptosis. A recent study suggested that SESN2 could counteract Toll-like receptor (TLR)-mediated proinflammatory signaling and cell apoptosis in macrophages ${ }^{38}$. Consistent with these observations, we noted that knockdown of SESN2 increased cell apoptosis, enhanced the activation of capsae-3, caspase-9, and elevated the ratio of $\mathrm{Bax} / \mathrm{Bcl}-2$ in DC2.4 cells treated with HMGB1. By contrast, SESN2 overexpression obviously alleviated HMGB1-induced cell death, evidenced by downregulating apoptotic rate and apoptotic-related proteins. Furthermore, in the in vivo experiments, the apoptosis was markedly elevated in sesn $2^{-1-}$ DCs after CLP. These data further confirm the protective impact of SESN2 on apoptosis of DCs in the setting of sepsis relevant condition.

We further focused on the response of ERS in DCs to explore the precise mechanisms underlying cytoprotective actions of SESN2 against apoptosis induced by HMGB1 or during sepsis. ERS, a double-edged sword, plays a critical role in modulating the balance between homeostasis and apoptosis of cells ${ }^{39,40}$. It is vital in the pathological process of inflammation and sepsis ${ }^{41}$, and appears to be one of the lethal contributors to immune dysfunction and lymphocyte apoptosis ${ }^{42}$. It has been demonstrated that the upregulation of SESN2 is uniquely induced under ERS response $^{43}$. Conversely, SESN2 exerts a marked influence on the response of ERS. In the current study, we noticed the co-location of SESN2 and ER, and SESN2 interacted with ATF4, indicating a close interaction between SESN2 with ERS response. Moreover, pretreatment with PERK inhibitor could obviously decrease the expression of SESN2 in DC2.4 cells induced by HMGB1, suggesting the significance of PERK signaling in regulation of SESN2 expression. It was reported that SESN2 protected against hepatocyte injury mediated by ERS, and related cell death was augmented in sesn $2^{-1-}$ mice $^{20}$. Thus, our data implicate the marked influence of SESN2 on ERS response in DCs exposed to acute inflammatory insults.

PERK-ATF4-CHOP pathway is one of the key mechanisms in ERS-related cell death ${ }^{44,45}$. CHOP is a necessary transcription factor for ERS-mediated cell demise in response to various pathological conditions ${ }^{44,46}$, and a critical signal to modulate the expression of Bcl-2 family member ${ }^{45-48}$. Herein, it was revealed that SESN2 inhibited the upregulation of $\mathrm{CHOP}$ expression induced by the prototypical ERS-mediated cell death in DC2.4 cells. HMGB1 stimulation resulted in significant activation of ERS signaling pathway, showing enhanced GRP78 expression and the activation of PERK, ATF4, as well as CHOP. Thus, the excessive ERS response under high concentration of HMGB1 contributed greatly to the apoptosis of DC2.4 cells, and SESN2 played an important role in protecting DCs against ERS-mediated apoptosis. In addition, it was found that the response of ERS and related cell death in DC2.4 cells under 


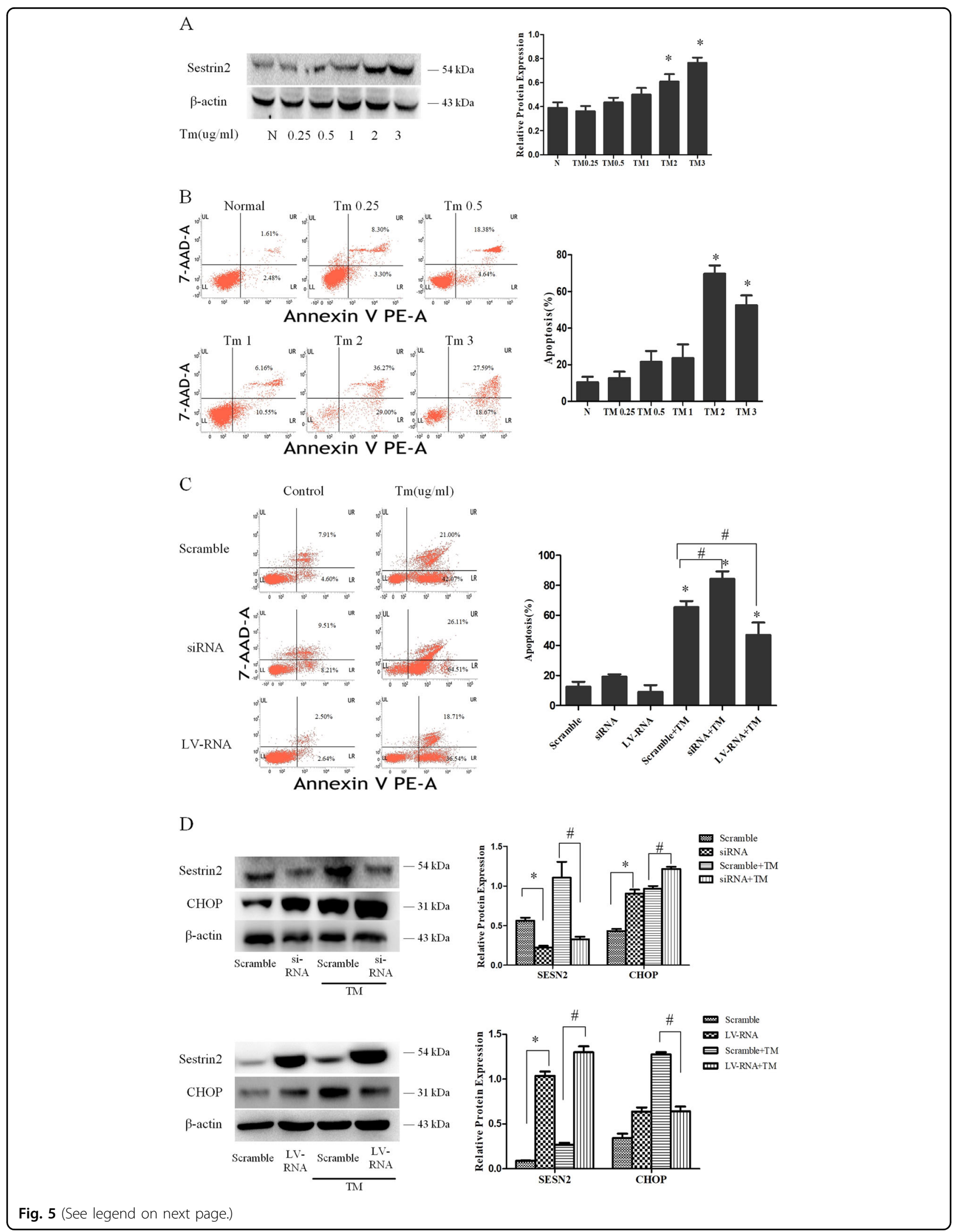


(see figure on previous page)

Fig. 5 SESN2 protected DC2.4 cells against ERS-related apoptosis triggered by TM. DC2.4 cells were treated with various dosages of TM ( 0.25 , $0.5,1$, and $100 \mathrm{ng} / \mathrm{ml}$ ) for $48 \mathrm{~h}$. Cells cultured for $48 \mathrm{~h}$ without TM were used as the controls. a PE-Annexin-V and 7-AAD were used to stain the treated DC2.4 cells and subjected to flow cytometry to assess cell apoptosis with different dosages of TM for $48 \mathrm{~h}$. $\mathbf{b}$ SESN2 expression was determined by Western blotting. c After modulated SESN2 expression, PE-Annexin V and 7-AAD were used to stain the treated DC2.4 cells and flow cytometry was used to assess cell apoptosis after stimulated with $2 \mu \mathrm{g} / \mathrm{ml} \mathrm{TM}$ for $48 \mathrm{~h}$. $\mathbf{d}$ Expressions of SESN2 and CHOP were measured as described in the section of methods following treatment with $2 \mu \mathrm{g} / \mathrm{ml} \mathrm{TM}$ for $48 \mathrm{~h}$. $\beta$-actin served as the internal standard. Data of three independent experiments were presented as the mean \pm SD. Statistical significance: ${ }^{*} P<0.05$ versus the scramble group; ${ }^{\#} P<0.05$ versus the scramble group treated with HMGB1.

HMGB1 stimulation was markedly aggravated after SESN2 knockdown. The distinctly upregulation of CHOP supported the notion that SESN2-knowdown led to ERS out of balance and inclined to apoptotic response. On the contrary, overexpression of SESN2 significantly alleviated ERS response, restored ER homeostasis, and abated ERSinduced cell death, by the evidences in downregulating ERS sensor and ERS-related apoptotic proteins. More importantly, PERK signaling inhibitor weakened the protective effect of SESN2 on DC2.4 cells evoked by HMGB1. In addition, the extent of ERS as well as ER morphology was distinctly exacerbated in sesn $2^{-1-}$ mice after sepsis, and sesn $2^{-1-}$ knockout increased 24-h mortality in mice suffered from septic challenge. Taken together, SESN2 appears to be an important regulator in protection against apoptosis of DCs induced by inflammatory stimulation, which is associated with PERKATF4-CHOP signaling transduction.

In the present experiments, we demonstrated for the first time that the activation of SESN2 in apoptotic signaling after HMGB1-stimulated DCs played a protective role in DC2.4 cells by regulating the extent of ERS response. HMGB1 or TM stimulation was able to enhance the expression of SESN2 and the apoptotic rate of DC2.4 cells. SESN2-knockdown exacerbated HMGB1-induced cell apoptosis via aggravating ERS response and ER dilation or fragmentation. Conversely, SESN2 overexpression remarkably attenuated HMGB1 or TMmediated cell apoptosis, and alleviated the morphologic alterations of ER and ERS response. Importantly, in a septic model of mice, knockout of SESN2 markedly aggravated the cell death of DCs mediated by ERS-related apoptosis. Thus, these results indicate that SESN2 appears to be a potential regulator to negatively modulate the apoptotic ERS response through inhibiting PERK-ATF4CHOP pathway and exerts a protective impact on apoptosis of DCs following septic insults.

Nonetheless, our study suffers from some limitations. Firstly, we do not show direct evidence that ERS-mediated DC apoptosis by interfering ER-related molecules, thus we cannot conclude that ERS-induced pathway plays a decisive and ultimate role in HMGB1-induced apoptosis of DCs. Secondly, due to the limited number of sesn $2^{-1-}$ mice, we only observed the survival rate of CLP mice at
$24 \mathrm{~h}$ without recording the 7 -day survival rate. Thirdly, it is deserve further study to elucidate the precise signaling pathways of ERS response by silencing ERS-related molecules in SESN2 transgenic mouse. Moreover, clinical studies should be followed to strengthen such interesting observation in the near future.

\section{Materials and methods Mice}

Six-week-old male, C57BL/6J mice (weight range 20-25 g) were provided by the Institute of Laboratory Animal Science, Peking Union Medical College, Beijing, China. Sesn $2^{-1-}$ mice in the C57BL/6J background were constructed by Shanghai Model Organisms Center, Shanghai, China. All mice were maintained in SPF conditions with a 12-h light/dark cycle. All experimental manipulations were conducted in accordance with the National Institutes of Health Guide for the Care and Use of Laboratory Animals, with the approval of the scientific Investigation Board of the Chinese PLA General Hospital, Beijing, China. WT and sesn $2^{-/-}$mice were randomly divided into two group, respectively: WT-sham group, WT-CLP group, sesn $2^{-1-}$-sham group, sesn $2^{-/-}$-CLP group, $n=6$ per sham group, $n=11-13$ per group.

\section{Reagents}

DC2.4 cells (the murine DC cell line) were purchased from ATCC, Shanghai, China. CD11c ${ }^{+}$(N418) MicroBeads were purchased from Miltenyi Biotec $\mathrm{GmbH}$, Bergisch Gladbach, Germany. Recombinant HMGB1 was purchased from R\&D System, Minneapolis, MI. TM was purchased from Sigma, St. Louis, MO. RPMI 1640, fetal calf serum, glutamine, penicillin, streptomycin, and HEPES were purchased from TianRunShanda Biotech Co. Ltd., Beijing, China. Annexin-V-PE and 7-AAD apoptosis detection kits were purchased from BD, San Diego, CA. Rabbit anti-mouse SESN2 (ab178518), rabbit anti-mouse GRP78 (ab21685), and rabbit anti-mouse ATF4 (ab184909) monoclonal antibodies were purchased from Abcam, Cambridge, MA. Rabbit anti-mouse caspase-3 (\#9662), mouse anti-mouse cleaved-caspase-3 (\#9661), mouse anti-mouse caspase-9 (\#9508), rabbit anti-mouse Bcl-2 (\#15071), rabbit anti-mouse Bax (\#2772), rabbit anti-mouse PERK (\#5683), rabbit anti-mouse p-PERK 


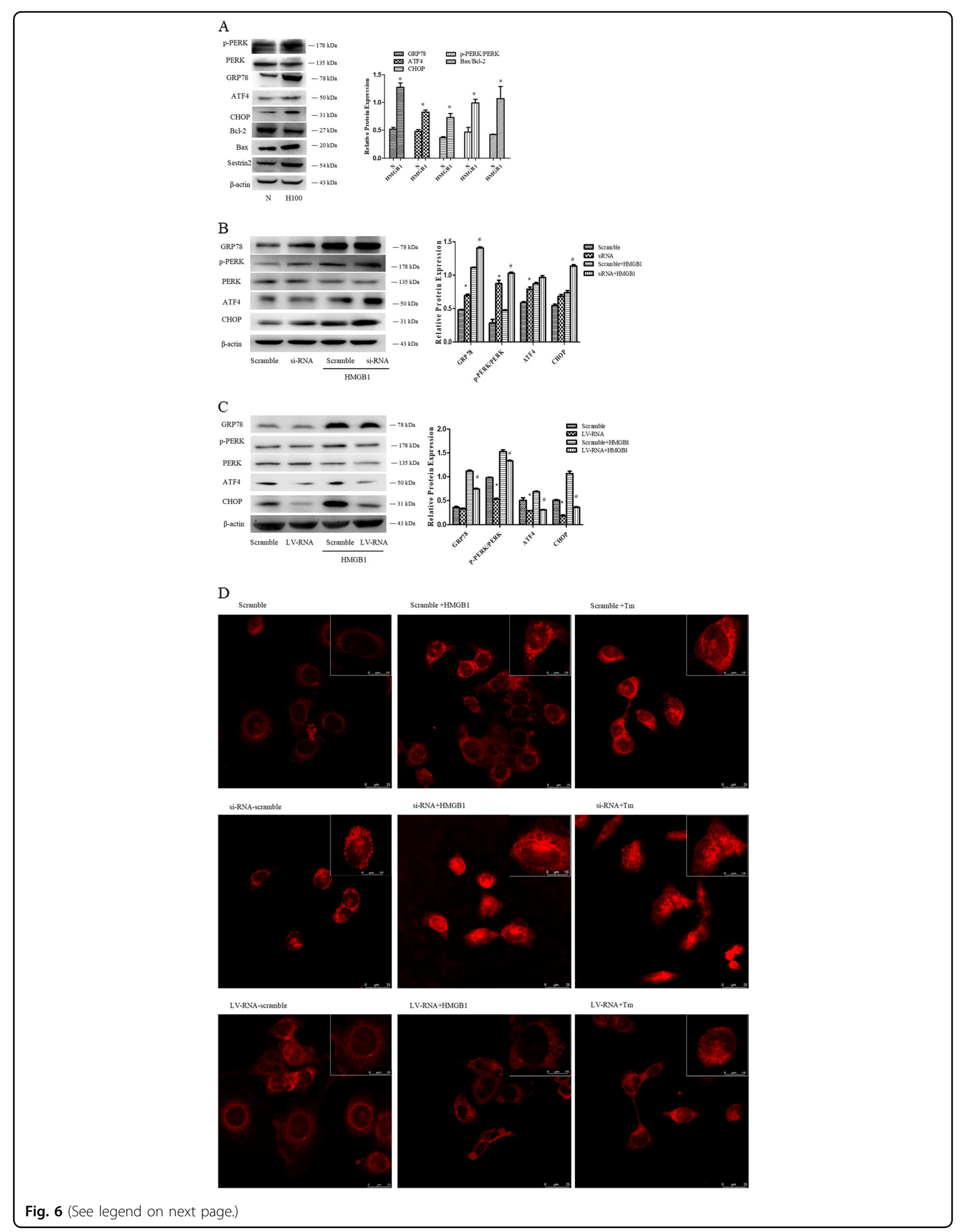


(see figure on previous page)

Fig. 6 SESN2 protected DC2.4 cells against excessive ERS response induced by HMGB1. a Expressions of GRP78, p-PERK, PERK, ATF4, CHOP, BCl2, and Bax were determined by Western blotting after treatment with $100 \mathrm{ng} / \mathrm{ml} \mathrm{HMGB1}$ for $48 \mathrm{~h}$. b, c Lentiviral vectors (SESN2 knockdown and SESN2 overexpression) were transduced DC2.4 cells, and scramble cells were transduced with blank vectors. After treated with $100 \mathrm{ng} / \mathrm{ml}$ HMGB1 for $48 \mathrm{~h}$, expressions of GRP78, p-PERK, PERK, ATF4, and CHOP were determined by Western blot analysis. $\mathbf{d}$ The morphologic alteration of ER in each cell was evaluated by immunofluorescence staining and the extent of the ER morphologic change was compared with the scramble controls ( $\times 600$, $\times 1200)$, scale bar $=25 \mu \mathrm{m}$, scale bar $=10 \mu \mathrm{m}, n=4$ per group. ER was detected with ER-tracker red. $\beta$-actin served as the internal standard. Data were presented as the mean $\pm S D, n=3$ per group. Statistical significance: ${ }^{*} P<0.05$ versus the control group.

(\#3179) monoclonal antibodies were purchased from Cell Signaling Technology, Danvers, MA. Mouse anti-mouse SESN2 (sc-393195) was purchased from Santa Cruz Biotechnology, Santa Cruz, CA. ER-tracker red was purchased from Invitrogen, California. Hoechst 33342 was purchased from R\&D System, Minneapolis, MI. Fluorescein isothiocyante (FITC)-mouse anti-rabbit IgG was purchased from Santa Cruz Biotechnology, Santa Cruz, CA. Triton X-100 was purchased from Sigma, St. Louis, MO. CoraLite594- conjugated goat anti-mouse IgG (H + L) was purchased from Proteintech Group, Rosemont, IL. Pierce co-IP kit was purchased from Thermo Fisher Scientific, Waltham, MA. GSK2656157 was purchased from was purchased from Selleckchem, Houston, TX.

\section{Mouse model of sepsis induced by CLP}

Polymicrobial sepsis was induced by CLP in mice. After anesthesia, the abdominal area was disinfected. A $1.0-\mathrm{cm}$ incision was performed along the midline of the abdomen, and then the cecum was identified and exposed. A specified percentage of the cecum was ligated and punctured twice with a 21-gauge needle, and then the cecum was punctured to induce sepsis. Next, the cecum was returned to abdominal cavity. After surgery, $1 \mathrm{ml}$ of $0.9 \%$ normal saline was injected subcutaneously. Mice exhibited lethargy, diarrhea and piloerection in the first $6 \mathrm{~h}$ after surgery, indicating the successful establishment of septic model. In the sham group, mice underwent the same surgical procedure except for the ligation and puncture step.

\section{Isolation of splenic DCs}

Under aseptic condition, mice spleens were obtained and washed in twice with precooled phosphate-buffered saline (PBS). Mononuclear cells were isolated, and then splenic DCs were isolated from murine mononuclear cells using a CD11 $\mathrm{c}^{+}$dendritic cell isolation kit (Miltenyi Biotec, Bergisch Gladbach, Germany) with a positive selection MS column following manufacturer's instructions. The selected DCs were obtained by centrifugation at $200 \mathrm{~g}$ for $10 \mathrm{~min}(\mathrm{~min})$, and the supernatant was discarded. Then these isolated cells were cultured in Roswel Park Memorial Institute medium (RPMI 1640) with $10 \%$ heated-inactivated FBS, containing $100 \mathrm{U} / \mathrm{ml}$ penicillin and $100 \mu \mathrm{l} / \mathrm{ml}$ streptomycin at $5 \% \mathrm{CO}_{2}, 37^{\circ} \mathrm{C}$ in a humidified incubator, or used for experiments.

\section{Cell culture and stimulation}

DC2.4 cells were cultured in RPMI 1640 with 10\% heated-inactivated FBS, containing $100 \mathrm{U} / \mathrm{ml}$ penicillin and $100 \mu \mathrm{l} / \mathrm{ml}$ streptomycin. Cells were cultured at $5 \% \mathrm{CO}_{2}$, $37^{\circ} \mathrm{C}$ in a humidified incubator. Before all experiments, cells were incubated for $24 \mathrm{~h}$. DC2.4 cells were cultured with or without HMGB1 stimulation (cultured with $10 \mathrm{ng} /$ ml HMGB1 for 8, 24, and $48 \mathrm{~h}$, or cultured with HMGB1 for $48 \mathrm{~h}$ at different concentrations of 1,10 , and $100 \mathrm{ng} / \mathrm{ml}$, respectively). After indicated stimulation, cells were collected for Western blot analysis and measurement by flow cytometry and laser scanning confocal microscope (LSCM, Leica, Mannheim, Germany), respectively.

\section{Total RNA extraction and reverse transcription-polymerase chain reaction analysis}

After cells were stimulated as indicated above, total RNA from DC2.4 cells $\left(2 \times 10^{6}\right)$ were extracted by using Trizol kits following manufacturer's instruction. Primers for SESN2 were 5'-GCTGCTGGATGAGAAGTTCC-3' (forward) and 5'-CCAAAGACGCAGTGGATGTA-3' (reverse). Primers for $\beta$-actin, a housekeeping gene, were 5'-TGCGTGACATCAAAGAGAAG-3' (forward) and 5' TCCATACCCAAGAAGGAAGG-3' (reverse). Thermal cycling conditions were $95^{\circ} \mathrm{C}$ for $10 \mathrm{~min}$, followed by 35 cycles of $95^{\circ} \mathrm{C}$ for $40 \mathrm{~s}(\mathrm{~s}), 60^{\circ} \mathrm{C}$ for $30 \mathrm{~s}$, and $72{ }^{\circ} \mathrm{C}$ for $25 \mathrm{~s}$, and a final extension period of $5 \mathrm{~min}$ at $72^{\circ} \mathrm{C}$.

\section{Western blot analysis and co-immunoprecipitation}

Cells $\left(3 \times 10^{6}\right)$ were collected and washed twice with ice-cold PBS, and lysed with lysis buffer $(150 \mathrm{mM} \mathrm{NaCl}$, $1.0 \%$ NP- 40 or $0.1 \%$ TritonX-100, $0.5 \%$ sodium deoxycholate, $0.1 \%$ sodium dodecyl sulfate (SDS), $50 \mathrm{mM}$ Tris- $\mathrm{HCl} \mathrm{pH}$ 8.0, protease inhibitors, and phosphatase inhibitors). After incubation on ice for $30 \mathrm{~min}$, the homogenate was centrifuged at $14,000 \mathrm{rpm}$ for $15 \mathrm{~min}$ at $4{ }^{\circ} \mathrm{C}$, and then boiled at $95^{\circ} \mathrm{C}$ for $5 \mathrm{~min}$ after mixing with SDS-loading buffer. The samples were separated with 8-12\% SDS polyacrylamide gel electrophoresis (Pulilai Co., Beijing, China), and then transferred to nitrocellulose membranes and blocked with $10 \%$ milk in TBST at 


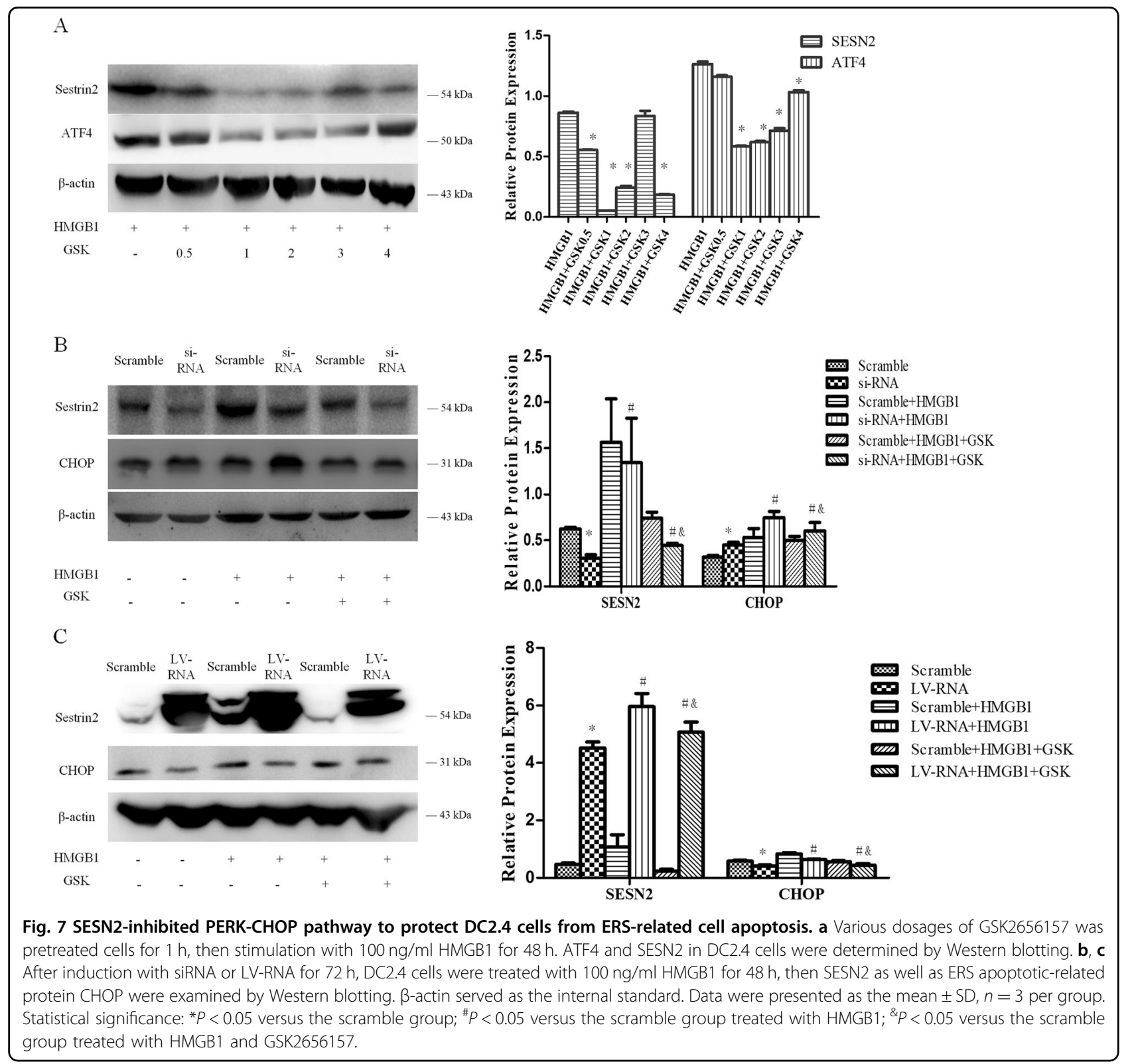

room temperature for $2 \mathrm{~h}$. Specific antibodies were used to determine expressions of SESN2, GRP78, CHOP, pPERK, PERK, ATF4, caspase-3, cleaved-caspase-3, caspase- $9, \mathrm{Bcl}-2$, and Bax, respectively. A monoclonal anti$\beta$-actin antibody was used as a control for protein loading. Immunoreactivity was visualized by ECL detection system (Amersham Biosciences, Uppsala, Sweden). Protein levels were quantified by densitometric analysis. Co-IP was done according to the manufacturer's protocol. SESN2 antibody was immobilized for 120 min using AminoLink Plus coupling resin. Then resin was washed and incubated with total cell lysate overnight at $4{ }^{\circ} \mathrm{C}$. After incubation, resin was washed twice and protein eluted by elution buffer. A negative control using control agarose resin to assess nonspecific binding received the same treatment as the co-IP samples. Samples were analyzed by Western blot analysis.

\section{Laser scanning confocal microscopy}

Morphological alterations of ER in DC2.4 cells and splenic DCs were performed by LCSM. The ER-tracker probe was used to selectively stain the ER of live cells. After incubating the cells for approximately $15-30 \mathrm{~min}$ at $37^{\circ} \mathrm{C}$, cells were collected and washed with PBS for three times, and fixed with $4 \%$ paraformaldehyde for $20 \mathrm{~min}$, then permeabilized with $0.1 \%$ Triton X-100 for 20 min at room temperature. Thereafter, cells were pre-blocked with $1 \%$ bovine serum albumin in distilled water for 


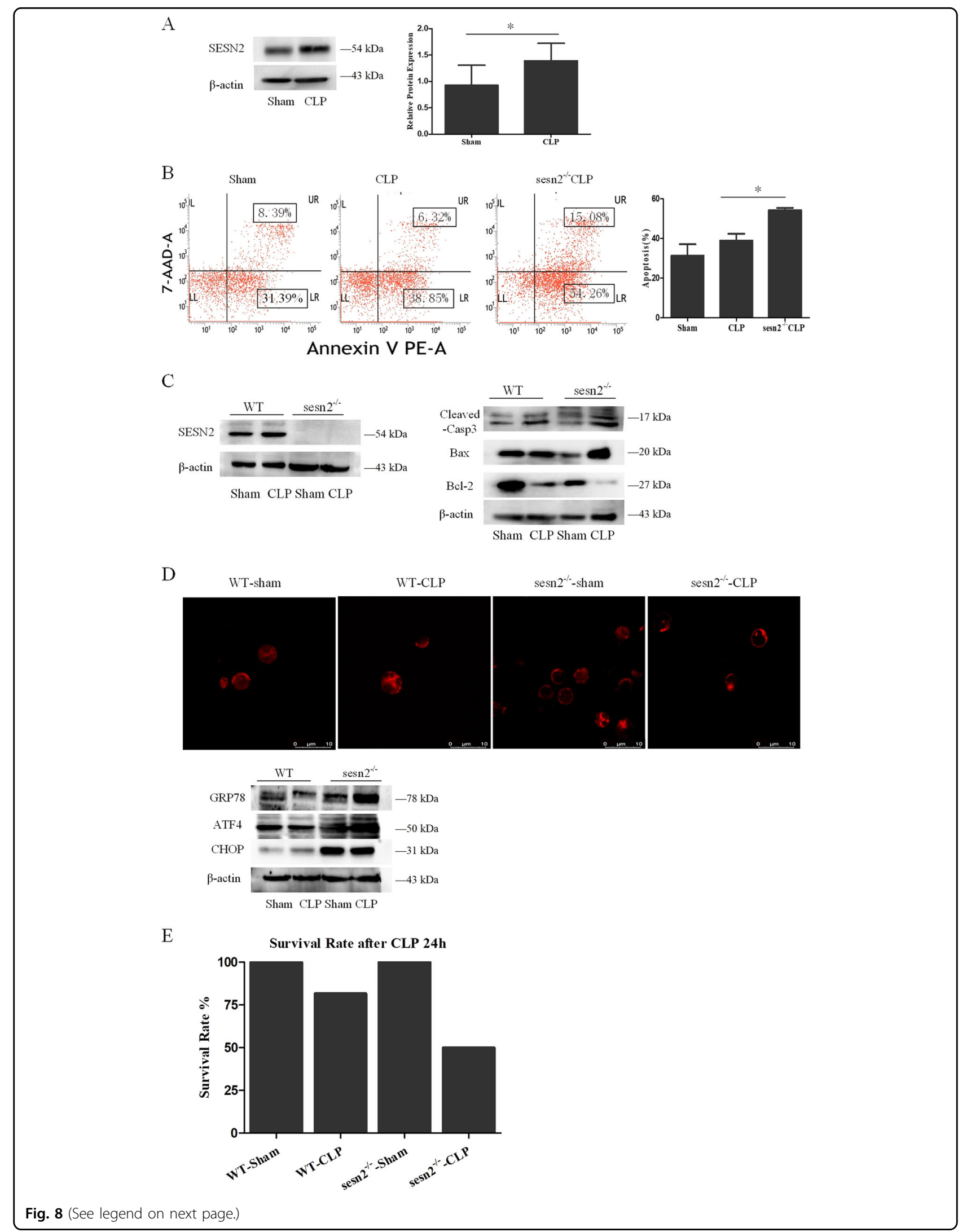


(see figure on previous page)

Fig. 8 The protective effect of SESN2 on DCs in CLP-induced septic mice. Mice underwent a sham procedure or CLP. a SESN2 expression was determined by Western blotting at $24 \mathrm{~h}$ after after CLP. $\mathbf{b}$ PE-Annexin-V and 7-AAD were used to stain DCs and subjected to flow cytometry to assess cell apoptosis at $24 \mathrm{~h}$ after CLP in vivo. c Expressions of cleaved-caspase-3, Bcl-2, and Bax were measured as described in the section of methods after CLP procedure. $\mathbf{d}$ In the sesn $2^{-/-}$CLP group, the morphologic alteration of ER in each cell was evaluated by immunofluorescence staining and the extent of the ER morphologic change was compared with the WT CLP group $(\times 1200)$. ER was detected with ER-tracker red. Levels of GRP78, ATF4, and $\mathrm{CHOP}$ were assessed by Western blotting. $\beta$-actin served as the internal standard. e The $24-\mathrm{h}$ survival rate of mice in the sesn2 ${ }^{-1-} \mathrm{CLP}$ group was markedly lower than that in the WT CLP group. Data of three independent experiments were presented as the mean $\pm S D, n=6$ per sham group, $n=11-13$ per CLP group. Statistical significance: ${ }^{*} P<0.05$ for in vivo comparison of the sesn ${ }^{-/-}$CLP group versus the WT CLP group.

30 min and stained with anti-SESN2 antibody (1:200) or anti-ATF4 antibody $(1: 200)$ or anti-GRP78 antibody (1:100) overnight at $4{ }^{\circ} \mathrm{C}$. By washed with PBS for three times, cells were stained with second antibody (FITCgoat-anti-IgG, PE-goat-anti-IgG) for $1 \mathrm{~h}$ at $37^{\circ} \mathrm{C}$ followed by PBS washes for three times. After being washed, the nuclei were stained with 4', 6-diamidino-2 -phenylindole (DAPI). The cells were observed using a laser scanning confocal microscope (Leica, Mannheim, Germany).

\section{Flow cytometric analysis}

The apoptotic rates of DCs were determined using simultaneous Annexin-V-PE and 7-AAD, and the negative control was designed. Cells $\left(5 \times 10^{5}\right)$ were cultured in 96-well flat bottom plates. After treatment with or without HMGB1, cells were collected and washed three times with cold PBS, and then resuspended in $100 \mu \mathrm{l}$ binding buffer, to which added $5 \mu \mathrm{l}$ Annexin-V-PE and $5 \mu \mathrm{l} \mathrm{7-}$ AAD. Incubation in darkness for $15 \mathrm{~min}$ at room temperature, the cells were diluted with $200 \mu$ l binding buffer and analyzed by flow cytometry within $1 \mathrm{~h}$ using a FACScan (BD Biosciences, Mountain View, CA).

\section{Hoechst 33342 analysis}

After stimulation with HMGB1 (100 ng/ml for $48 \mathrm{~h}$ ), morphological changes in apoptotic DC2.4 cells were measured by nuclear staining with the bisbenzimidazole dye Hoechst 33342 solution. Cells were exposed to $5-10 \mu \mathrm{g} / \mathrm{ml}$ Hoechst 33342 solution at $37^{\circ} \mathrm{C}$ for 30-60 min. Then Hoechst 33342 solution was removed from cells, and fluorescence microscopy was used to evaluate the apoptotic cells with image representative fields for each experiment.

\section{SESN2 RNA lentivirus generation and transfection}

Over-expression RNA to SESN2 (SESN2-LV-RNA) or small interference RNA to SESN2 (SESN2-siRNA) was synthesized by Hanbio Biotechnology Co., Shanghai, China. For over-expression or knockdown of SESN2 expression, DC2.4 cells were introduced with recombinant lentiviruses that carried the SESN2-LV-RNA or SESN2-siRNA. The recombinant lentiviruses were transduced according to the manufacture's instruction. The transduction efficiency for DC2.4 cells in vitro was $>80 \%$. After transfection for 3 days, the efficiency of overexpression or knockdown was checked by Western blotting for SESN2 expression.

\section{Statistical analysis}

All results were represented as mean \pm standard deviation of more than three independent experiments. Oneway analysis of variance (ANOVA) was used to analyze significant differences among the groups, and student $t$ test was needed for assessing significant differences of intergroup. $P$ values less than 0.05 were considered statistically significant.

\section{Acknowledgements}

This work was supported by grants from the National Natural Science Foundation of China (Nos. 81730057 and 81871557), the Military Medical Innovation Program of Chinese PLA (No. 18CXZ026), the National Key Research and Development Program of China (No. 2017YFC1103302), and the Lijiang Scholars Program.

\section{Author details}

${ }^{1}$ Trauma Research Center, Fourth Medical Center of the Chinese PLA General Hospital, Beijing 100048, PR China. ${ }^{2}$ First Medical Center of the Chinese PLA General Hospital, Beijing 100853, PR China. ${ }^{3}$ Department of Burns and Plastic Surgery, 924th Hospital of Chinese PLA, Guilin 541002, PR China. ${ }^{4}$ State Key Laboratory of Kidney Disease, the Chinese PLA General Hospital, Beijing 100853, PR China

Conflict of interest

The authors declare that they have no conflict of interest.

\section{Publisher's note \\ Springer Nature remains neutral with regard to jurisdictional claims in published maps and institutional affiliations.}

Supplementary Information accompanies this paper at (https://doi.org/ 10.1038/s41419-020-2324-4).

Received: 10 October 2019 Revised: 31 January 2020 Accepted: 3 February 2020

Published online: 18 February 2020

\section{References}

1. Pearce, E. J. \& Everts, B. Dendritic cell metabolism. Nat. Rev. Immunol. 15, 18-29 (2015).

2. Said, A. \& Weindl, G. Regulation of dendritic cell function in inflammation. J. Immunol. Res. 2015, 1-15 (2015). 
3. Hotchkiss, R. S. et al. Depletion of dendritic cells, but not macrophages, in patients with sepsis. J. Immunol. 168, 2493-2500 (2002).

4. Tinsley, K. W. et al. Sepsis induces apoptosis and profound depletion of splenic interdigitating and follicular dendritic cells. J. Immunol. 171, 909-914 (2003).

5. Gautier, E. L. et al. Enhanced dendritic cell survival attenuates lipopolysaccharide-induced immunosuppression and increases resistance to lethal endotoxic shock. J. Immunol. 180, 6941-6946 (2008).

6. Efron, P. A. et al. Characterization of the systemic loss of dendritic cells in murine lymph nodes during polymicrobial sepsis. J. Immunol. 173, 3035-3043 (2004).

7. Kushwah, R. \& Hu, J. Dendritic cell apoptosis: regulation of tolerance versus immunity. J. Immunol. 185, 795-802 (2010).

8. Travers, K. J. et al. Functional and genomic analyses reveal an essential coordination between the unfolded protein response and ER-associated degradation. Cell 101, 249-258 (2000).

9. Wang, M. \& Kaufman, R. J. Protein misfolding in the endoplasmic reticulum as a conduit to human disease. Nature 529, 326-335 (2016).

10. Szegezdi, E., Logue, S. E., Gorman, A. M. \& Samali, A. Mediators of endoplasmic reticulum stress-induced apoptosis. EMBO Rep. 7, 880-885 (2006).

11. Moretti, J. \& Blander, J. M. Cell-autonomous stress responses in innate immunity. J. Leukoc. Biol. 101, 77-86 (2017).

12. Bettigole, S. E. \& Glimcher, L. H. Endoplasmic reticulum stress in immunity. Annu Rev. Immunol. 33, 107-138 (2015).

13. Zhu, X. M. et al. The effect of high mobility group box-1 protein on splenic dendritic cell maturation in rats. J. Interferon Cytokine Res. 29, 677-688 (2009).

14. Zhu, X. M. et al. Endoplasmic reticulum stress and its regulator XBP-1 contributes to dendritic cell maturation and activation induced by high mobility group box-1 protein. Int J. Biochem. Cell Biol. 44, 1097-1105 (2012).

15. Zhu, X. M. et al. The involvement of endoplasmic reticulum stress response in immune dysfunction of dendritic cells after severe thermal injury in mice. Oncotarget 8, 9035-9052 (2017).

16. Lee, J. H. et al. Maintenance of metabolic homeostasis by Sestrin2 and Sestrin3. Cell Metab. 16, 311-321 (2012).

17. Budanov, A. V. et al. Identification of a novel stress-responsive gene Higs involved in regulation of cell viability. Oncogene 21, 6017-6031 (2002).

18. Hay, N. p53 strikes mTORC1 by employing sestrins. Cell Metab. 8, 184-185 (2008).

19. Ding, B. et al. Sestrin2 is induced by glucose starvation via the unfolded protein response and protects cells from non-canonical necroptotic cell death. Sci. Rep. 6, 22538 (2016).

20. Park, H. W. et al. Hepatoprotective role of Sestrin2 against chronic ER stress. Nat. Commun. 5, 4233 (2014)

21. Saveljeva, S. et al. Endoplasmic reticulum stress-mediated induction of SESTRIN 2 potentiates cell survival. Oncotarget 7, 12254-12266 (2016).

22. Brüning, A., Rahmeh, M. \& Friese, K. Nelfinavir and bortezomib inhibit mTOR activity via ATF4-mediated sestrin-2 regulation. Mol. Oncol. 7, 1012-1018 (2013).

23. Jegal, K. H. et al. Activating transcription factor 6-dependent sestrin 2 induction ameliorates ER stress-mediated liver injury. Biochim. Biophys. Acta 1864 1295-1307 (2017)

24. Budanov, A. V., Lee, J. H. \& Karin, M. Stressin' Sestrins take an aging fight. EMBO Mol. Med. 2, 388-400 (2010).

25. Singer, M. et al. The Third International Consensus Definitions for sepsis and septic shock (Sepsis-3). J. Am. Med. Assoc. 315, 801-810 (2016).
26. Hotchkiss, R. S. \& Nicholson, D. W. Apoptosis and caspases regulate death and inflammation in sepsis. Nat. Rev. Immunol. 6, 813-822 (2006).

27. Boomer, J. S. et al. Immunosuppression in patients who die of sepsis and multiple organ failure. J. Am. Med. Assoc. 306, 2594-2605 (2011).

28. Guisset, O. et al. Decrease in circulating dendritic cells predicts fatal outcome in septic shock. Intensive Care Med. 33, 148-152 (2007)

29. Bouras, M., Asehnoune, K. \& Roquilly, A. Contribution of dendritic cell responses to sepsis-induced immunosuppression and to susceptibility to secondary pneumonia. Front. Immunol. 9, 2590 (2018).

30. Kang, R. et al. HMGB1 in health and disease. Mol. Asp. Med. 40, 1-116 (2014).

31. Deng, M., Scott, M. J., Fan, J. \& Billiar, T. Location is the key to function: HMGB1 in sepsis and trauma-induced inflammation. J. Leukoc. Biol. 106, 161-169 (2019).

32. Andersson, U., Yang, H. \& Harris, H. High-mobility group box 1 protein (HMGB1) operates as an alarmin outside as well as inside cells. Semin. Immunol. 38, 40-48 (2018).

33. Yang, D. et al. High mobility group box-1 protein induces the migration and activation of human dendritic cells and acts as an alarmin. J. Leukoc. Biol. 81, 59-66 (2007).

34. Dumitriu, I. E. et al. Release of high mobility group box 1 by dendritic cells controls $T$ cell activation via the receptor for advanced glycation end products. J. Immunol. 174, 7506-7515 (2005).

35. Saenz, R. et al. TLR4-dependent activation of dendritic cells by an HMGB1derived peptide adjuvant. J. Transl. Med. 12, 211 (2014).

36. Julien, O. \& Wells, J. A. Caspases and their substrates. Cell Death Differ. $\mathbf{2 4}$ 1380-1389 (2017)

37. Ben-Sahra, I. et al. Sestrin2 integrates Akt and mTOR signaling to protect cells against energetic stress-induced death. Cell Death Differ. 4, 611-619 (2013).

38. Yang, J. H. et al. Role of sestrin2 in the regulation of proinflammatory signaling in macrophages. Free Radic. Biol. Med. 78, 156-167 (2015).

39. Hetz, C. \& Papa, F. R. The unfolded protein response and cell fate control. Mol. Cell. 69, 169-181 (2017).

40. Crouser, E. D. Sepsis-induced endoplasmic reticulum stress: a matter of life and death? Crit. Care Med. 44, 1626-1627 (2016).

41. Kozlov, A. V. et al. Endotoxin causes functional endoplasmic reticulum failure, possibly mediated by mitochondria. Biochim. Biophys. Acta 6, 521-530 (2009).

42. $\mathrm{Ma}$, T. et al. The endoplasmic reticulum stress-mediated apoptosis signal pathway is involved in sepsis-induced abnormal lymphocyte apoptosis. Eur. Surg. Res. 41, 219-225 (2008).

43. Kim, H. J. et al. Carbon monoxide protects against hepatic steatosis in mice by inducing sestrin-2 via the PERK-elF2a-ATF4 pathway. Free Radic. Biol. Med. 110 81-91 (2017).

44. Han, J. et al. ER-stress-induced transcriptional regulation increases protein synthesis leading to cell death. Nat. Cell Biol. 15, 481-490 (2013).

45. Liu, Z., LV, Y., Zhao, N., Guan, G. \& Wang, J. Protein kinase R-like ER kinase and its role in endoplasmic reticulum stress-decided cell fate. Cell Death Dis. 6, e1822 (2015).

46. Yang, Y. et al. Transcription factor C/EBP homologous protein in health and diseases. Front. Immunol. 8, 1612 (2017).

47. Tabas, I. \& Ron, D. Integrating the mechanisms of apoptosis induced by endoplasmic reticulum stress. Nat. Cell Biol. 13, 184-190 (2011).

48. Rozpedek, W. et al. The role of the PERK/elF2a/ATF4/CHOP signaling pathway in tumor progression during endoplasmic reticulum stress. Curr. Mol. Med. 16, 533-544 (2016). 